http://jmscr.igmpublication.org/home/ ISSN (e)-2347-176x ISSN (p) 2455-0450 crossref DOI: https://dx.doi.org/10.18535/jmscr/v8i9.13

\author{
Journal Of Medical Science And Clinical Research \\ IGM Publication \\ An Official Publication of IGM Publication
}

\title{
Intra-spinal Neurenteric Cyst in an adult- a case report of a rare anomaly
}

\author{
Authors \\ Meghadipa Mandal ${ }^{1}$, Anadi Roy Chowdhury ${ }^{2}$ \\ Kolkata-700102 India
}

${ }^{1}$ Post Graduate trainee, Department of Pathology, R. G. Kar Medical College \& Hospital, West Bengal,

${ }^{2}$ Department of Pathology, R. G. Kar Medical College \& Hospital, West Bengal, Kolkata-700102 India

\begin{abstract}
Neurenteric cysts are rarely encountered congenital anomalies that result from abnormal connection between endoderm and ectoderm in third week of intrauterine life. They may have varied clinical symptoms and age of presentation. Our case presented in mid years with gradually progressive lower limb radiculopathy, along with tingling and numbness. MRI revealed an intradural cystic mass in lumbar region. Full surgical excision was done and histopathological examination revealed an endoderm- lined cystic space. Hence, the diagnosis of Intraspinal Neurenteric cyst was made.
\end{abstract}

Keywords: Neurenteric cyst, Spinal cord, congenital anomaly, radiculopathy.

\section{Introduction}

Neurenteric cysts are rarely encountered\& reported entities that result from incomplete separation of developing endodermal and notochordal tissues in early embryonic life, more so, during third week of embryonic life $\mathrm{e}^{[1]}$. They have been variously named as- endodermal cysts, enterogenous cyst, enteric cyst, gastrocytoma, dorsal enteric fistula, split notochord syndrome and teratoid $\mathrm{cyst}^{[1,2]}$. The heterotopic rests of epithelium reminiscent of gastrointestinal and respiratory tissue lead to eventual formation of compressive cystic lesions of the pediatric and adult spine ${ }^{[3]}$.

The presentation may be varied ranging from isolated intra-spinal cysts to widespread vertebral or visceral anomalies like intestinal malformations $\&$ dermal sinuses ${ }^{[2]}$, especially where there is persistence of entire primitive Neurenteric canal. Isolated Neurenteric cyst may simply present as size dependent myelopathic and/or radicular signs $^{[3]}$. Radiologically, they are most commonly situated anterior to the spinal cord ${ }^{[2]}$.

Here, we present such an isolated intraspinal, intradural and extra medullary Neurenteric cyst.

\section{Clinical Presentation}

Here we present a case of 48 years old male patient with history of gradually progressive pain in bilateral lower limbs, associated with tingling and numbness for the past 3 years. There was no discernable weakness in any of the limbs and initially, the patient could carry out his regular activities. There was gradual worsening of the symptoms, which were not relieved with physiotherapy and conservative management. The patient underwent a Magnetic Resonance Imaging (MRI) of the spine that showed a cystic mass, which was intradural and extra medullary, extending from L1 to L3 lumbar vertebra (Figure $1 \&$ Figure 2). 


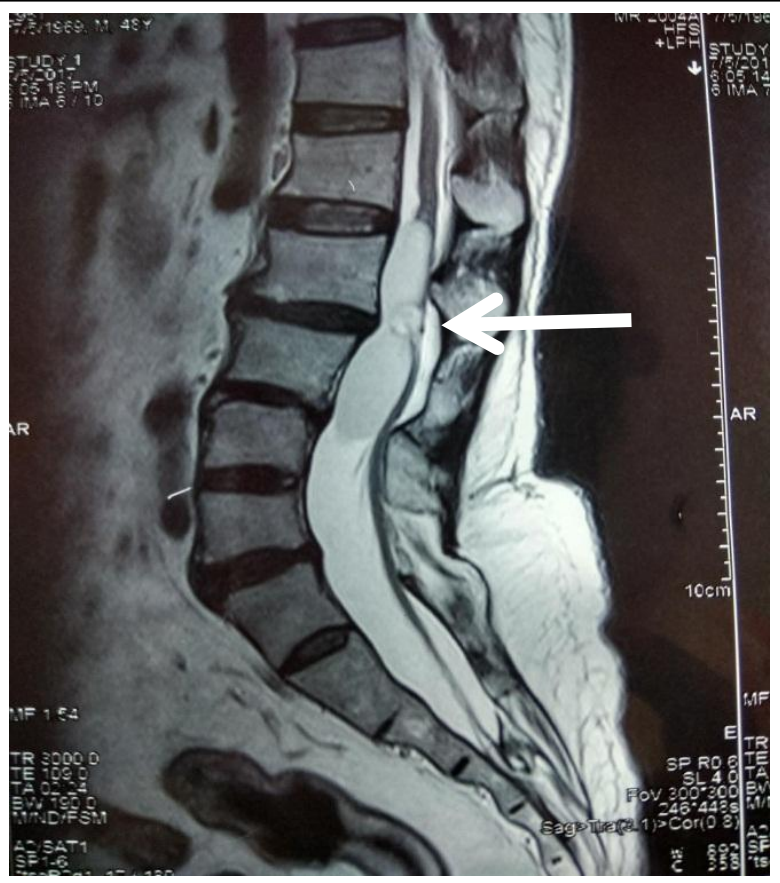

Figure 1: MRI of spine showing a wellcircumscribed cystic lesion (shown by arrow)

Radiologically, the cyst had a smooth margin and was removed in entirety through operative intervention. The entire cystic mass was sent for histopathological examination.

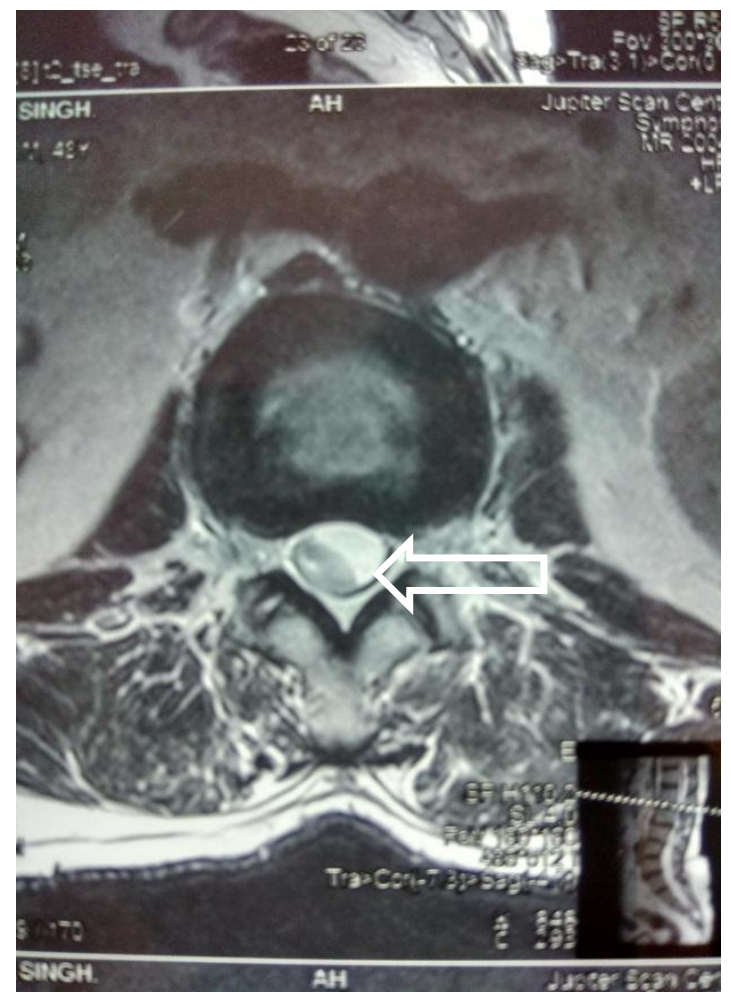

Figure 2: MRI of spine showing Neurenteric cyst (Axial view, shown by open arrow)

\section{Grossing}

On gross examination, it was a cystic structure measuring $3 \mathrm{~cm} \times 2 \mathrm{~cm} \times 2 \mathrm{~cm}$. Cut-section revealed a multi-loculated cyst with wall thickness of 2-3 mm, filled with gelatinous material. Serial sections were given from the cyst wall and sent for routine processing, and haematoxylin and eosin (H \& E) staining.

\section{Histopatological Study}

On serial sections being examined, the cyst lining was seen to be ciliated cuboid to columnar type, with few areas showing pseudo stratification (Figure 3 \& 4), thrown into a villous-like architecture Figure 5). The lining epithelium showed resemblance to Enteric \& Respiratory mucosa. There were also areas showing Stratified Squamous type lining. There was no atypia noted in the epithelial lining.

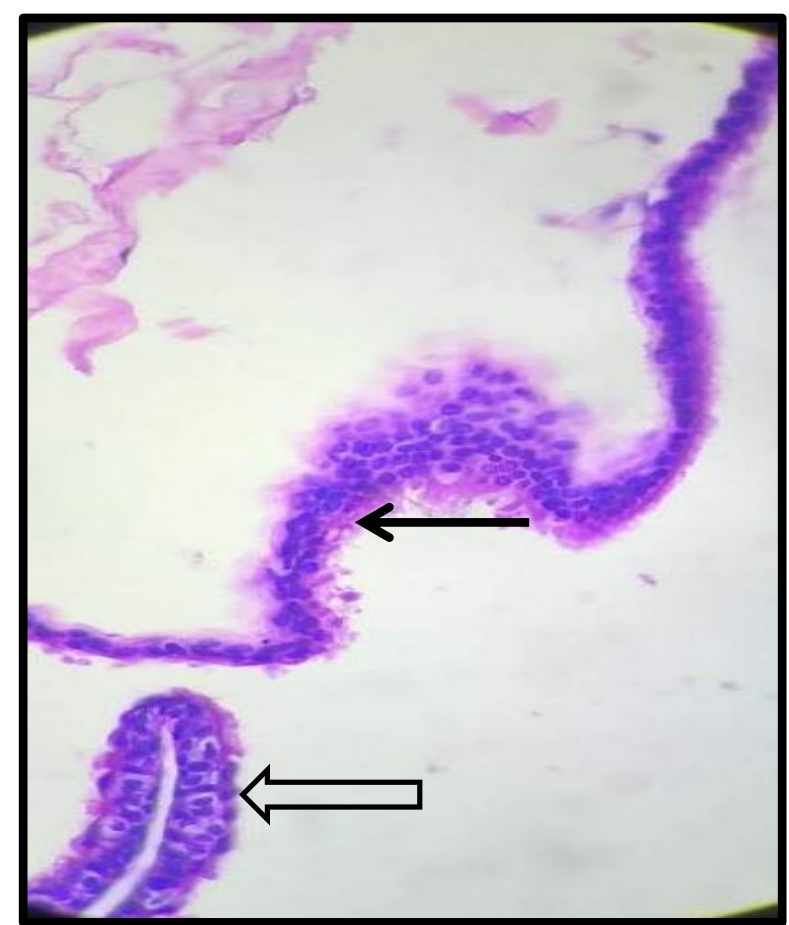

Figure 3: H\&E stained section of cyst wall (Closed arrow- Pseudo stratified ciliated columnar epithelium; Open arrow- Ciliated Cuboidal epithelium, 400X magnification)

Thus, a diagnosis of Intraspinal Neurenteric cyst was made. 


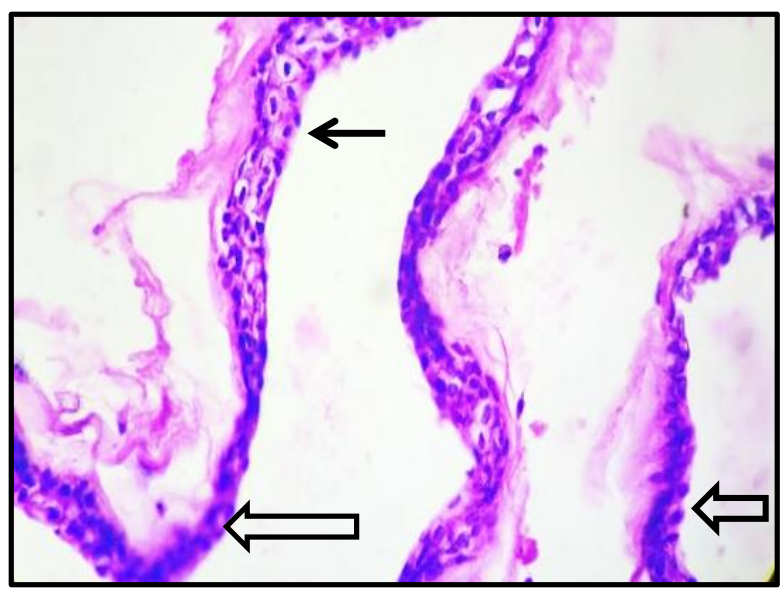

Figure 4: H\&E stained section of Cyst wall (Closed arrow- Stratified Squamous lining; Open arrow- Ciliated Columnar lining, 400X Magnification)

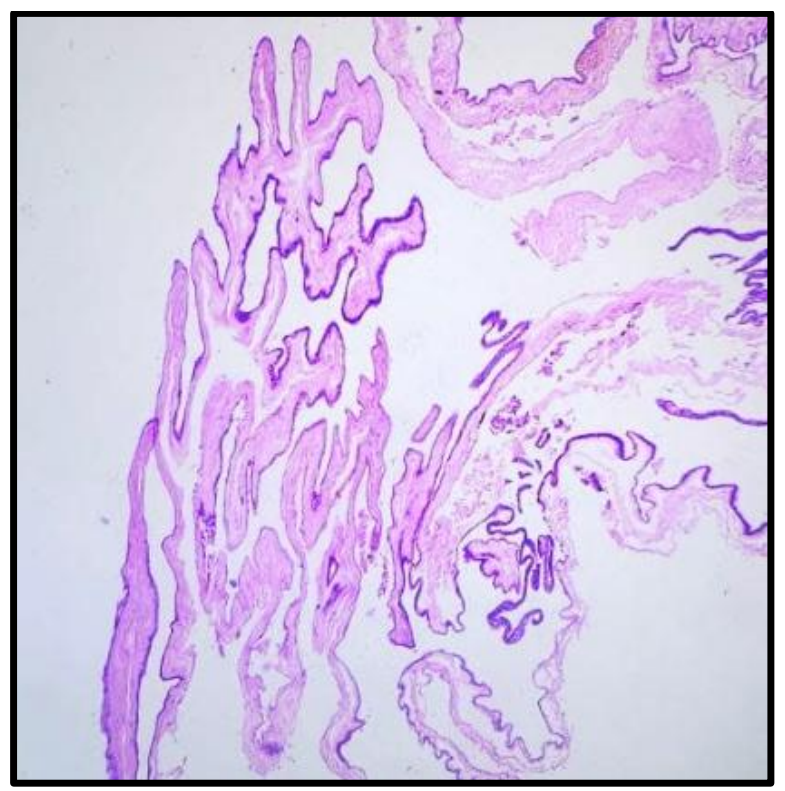

Figure 5: H\&E section of cyst wall thrown into villous-like folds (100X magnification)

\section{Discussion}

Neurenteric cysts typically present with spinal cord or cranial nerve compression, as was seen in our case where he gradually developed increasing lower limb radicular pain, associated with tingling and numbness.

Cases may have a wide age range of presentation, from 5 weeks to 52 years $^{[1]}$. In our case it was a middle-aged man. Similarly, the clinical scenario may also vary from asymptomatic cysts discovered as an incidental radiological finding, to widespread vertebral anomalies like lipomadiastomatomyelia gut cysts \& bowel duplication. The most common location of Neurenteric cyst is cervico- dorsal ${ }^{[4]}$ that maypresent as anterior fusion defects ${ }^{[5]}$ like anterior spina bifida, cleft vertebrae, hemi vertebrae, scoliosis and widened interpediculate distances.

The cases that present early with other associated visceral anomalies are rather easily detected than the ones that have a relatively late presentation with non-specific, low-grade symptoms that otherwise, do not demand medical attention. This was the situation with our case.

They result from failure of separation of ectoderm from the endoderm during the third week of embryonic life with persistent canal of Kovalevsky. The nature of the eventual abnormality depends on the extent to which this adhesion subsequently disappears. Persistence of the entire tract results in the extreme form of combined anterior and posterior spina bifida with dorsal enteric fistula. Persistence of only a part of the tract produces the isolated intraspinal cyst ${ }^{[4]}$, as was seen in this case.

Imaging modality by MRI is the best for diagnosing these cystic lesions.

Most commonly, these cysts are lined by columnar lining. But occasionally, they may have respiratory or gastroenteric-type mucosa and organized supporting elements like seromucinous glands, muscularis mucosae, cartilaginous rings, ganglion cells, i.e., of the developed alimentary tract or tracheo-bronchial tree ${ }^{[2]}$. Hence, based on these different histological variants, Wilkins and Odome classified it into 3 types:

Type I: Single pseudostratifed, cuboidal or columnar epithelium with or without cilia lying on a basement membrane.

Type II: Similar to type I with addition of mucous glands, serous glands, smooth muscle, fat, cartilage, bone, elastic fibers, lymphoid tissue or nerve ganglion.

Type III: Similar to type II with addition of ependymal or glial tissue. 
The case discussed in this reporting belongs to Type I of Wilkins and Odome Classification. However, most of the Neurenteric cysts belong to group $\mathrm{II}^{[1]}$.

The wall of these cysts takes up immunohistochemical stains such as cytokeratin, epithelial membrane antigen (EMA) and Carcinoembryonic Antigen (CEA), while it is negative for S100 and glial fibrillary acidic protein (GFAP) which confirms their endodermal origin $^{[6]}$ However, routine lab practice does not warrant the use of Immunohistochemistry (IHC). The final diagnosis depends on the histological assessment of the cysts.

\section{Conclusion}

Neurenteric cyst is unique in terms of its rare incidence of occurrence. They may demand late clinical attention owing to its asymptomatic or mildly symptomatic non-specific presentation. However, MRI \& Histological aids are sufficient to clinch the diagnosis.

\section{References}

1. Khadim MT, Asif M, Ali Z. Intraspinal Neurenteric Cyst - a rare entity. J Pak Med Assoc. 2011; 11: 1143-45.

2. Goldblum JR, Lamps LW, McKenney JK, Myers JL. Rosai and Ackerman's Surgical Pathology 2018; pp 1953.

3. Savage JJ, Casey JN, McNeill IT, Sherman JH. Neurenteric cysts of the spine 2010; 1(1): 58-63.

4. Sreedhar M, Menon S, G Varma G, Ghosal N. Cervico-Thoracic Neurenteric Cyst - A Case Report. Ind J Radiol Imag 2006; 16(1):99-102.

5. Wilson ES Jr. Neurenteric cyst of the mediastinum. American Journal of Roentgenology 1969; 107(3): 641-646.
6. Kapoor V, Johnson DR, Fukui MB, Rothfus WE, Jho HD. Neuroradiologicpathologic correlation in a neurenteric cyst of the clivus. AJNR Am J Neuroradiol 2002; 23: 476-9. 